\title{
PERCEPTIONS OF WOMEN ABOUT BREAST CANCER IN RURAL AREA OF WARDHA DISTRICT
}

\author{
Gondnale Goral N ${ }^{1}$, Ingole Abhishek ${ }^{1}$, Mudey Abhay ${ }^{1}$, Kshatrapal Prajapati ${ }^{2}$ \\ ${ }^{1}$ Department of Community Medicine, Jawaharlal Nehru Medical College, DMIMSU, Wardha, Maharashtra, \\ ${ }^{2}$ Department of Community Medicine, Govt Medical College, Shivpuri, Madhya Pradesh, India.
}

\begin{abstract}
Background: The incidence of breast cancer is seen to be low in India as compared to western countries, however the mortality is low. The knowledge about breast cancer, breast awareness and self-breast examination is the need of the hour. Breast Cancer, if caught in the early stages, makes it curable by various modalities of treatment. Our study aims here to qualitatively explore the views and ideas of the women in rural area about breast cancer and the need of a better comprehensive program. Method: A community based cross-sectional study was carried out with a sample size of 672 with a pre-tested questionnaire with open-ended questions for qualitative exploration. It was done by door-to-door survey. Resident females of the village above 30years were included and females with chronic illness and temporary residents were excluded. Results: The mean age of participants was $42.38 \pm 9.76$ years with $48.2 \%$ educated till secondary school and $83.2 \%$ belonged to OBC category. The perceptions were assessed with qualitative findings where it was found that most of the females believed that they don't have breast cancer even before getting screened and so they didn't want to get mammography. However they affirmed that a doorstep approach of activities would be beneficial. They also said that doorstep activities help get good information of breast cancer signs and symptoms and program like this will be a good approach. Conclusion: Doorstep approach can be a welcome change in imparting awareness.
\end{abstract}

Keywords: Breast Cancer; Awareness; Wardha.

\section{INTRODUCTION}

India is experiencing a rapid health transition with rise in the burden of Non-communicable diseases. In India, oral and lung cancers are common amongst both genders. Breast cancer is the most common cancer in urban areas while the second most common in rural areas in females accounting to $27 \%$ of the total cancers [1]. It is predicted to be the common type of cancer in the coming decade. According to National Cancer Registry Programme Projections, the number of cancer cases will increase to 134214 in 2015 and to 179790 by 2020 [2].

Though the incidence of breast cancers is more in western countries as compared to India, The mortality remains unchanged. This is due to the fact the higher proportions of cases are diagnosed in advanced stages in India due to lack of awareness, intimidation and unavailability of a good screening programme. Less than $3 \%$ of the patient Indian women undergo screening for breast cancer [3].

Government of India launched National Programme for Prevention and Control of Cancers, Diabetes, Cardiovascular Diseases and Stroke (NPCDCS) during 201011 after integrating the National Cancer Control Programme (NCCP) with National Programme for Prevention and Control of Diabetes, Cardiovascular Diseases

\begin{tabular}{l} 
DOI: $0.31878 /$ ijcbr.2018.51.08 \\
iSSN: $2395-0471$ \\
\hline
\end{tabular}

and Stroke (NPDCS). The focus of NPCDCS is on promotion of healthy lifestyles, early diagnosis and management of diabetes, hypertension, cardiovascular diseases and common cancer e.g. cervix cancer, breast cancer and oral cancer. Under this programme, various efforts are made for health promotion, early diagnosis, treatment and formulation of tertiary care centres for cancer [4].

However, there is a lack of a community based approach for the awareness and screening of breast cancer under the programme, especially in the rural India where females are intimidated about coming out and talking about their health problems.

In India, the age incidence shows the presence of breast cancer to be higher in younger age, more in the age group of 40-50years for unknown reasons. So the knowledge about breast cancer, breast awareness and self-breast examination is the need of the hour. Breast Cancer, if caught in the early stages, makes it curable by various modalities of treatment. A lack of proper knowledge about health care and self-care in females makes it difficult for females to approach the health facility till the end-stage of cancer. Hence resulting in the high mortality.

The current study therefore aims here to qualitatively explore the views and ideas of the women in rural area about breast cancer and the need of a better comprehensive program.

\section{METERIALS AND METHODS}

Study design: A cross sectional descriptive study

Correspondence: : Dr. Ingole Abhishek, Dhanwantari Nagar, Warud Road, Sevagram, Wardha, Maharashtra. E-mail: ingole.abhishek@gmail.com

(C) Authors; 2019. International Journal of Clinical and Biomedical Research, Sumathi Publications.

This is an Open Access article which permits unrestricted non-commercial use, provided the original work is properly cited. 
Ethics approval: The study was approved by the institutional ethics committee and informed consent was taken from the participants. Permission was taken from the program convener of DMIMS, Wardha (Sawangi) for carrying out the study.

Study place: Study was carried out in the Yelakeli village, Tahsil Seloo, District Wardha, which comes under the Field Practice Area of Department of Community Medicine of the tertiary care hospital, Acharya Vinoba Bhave Rural Hospital, Sawangi (Meghe).

Study Duration: The study was conducted in the months of March and April 2018.

Sample Size: The Population of Yelakeli village as per Census 2011 and Gram Panchayat is 4923. Total females of Yelakeli (as per data from Grampanchayat and Census 2011) was 2080. Considering $40 \%$ population above 30years age group (as per Census 2011)(5).

Sample Size Calculated $=40 \%$ of $2080=832$.

Inclusion Criteria: Resident Females of Yelakeli Village above the age of 30 years who are not already a diagnosed case of Breast Cancer or any other cancer and willing to participate were included in the study.

Exclusion Criteria: Females already diagnosed of Breast Cancer or cervical cancer irrespective of their treatment status, chronically ill or bedridden females and females who are temporary residents of the village were excluded from the study.

Data Collection Process: Four simple open-ended questions were framed to be asked to all the female participants in door-to-door survey which was a part of an interventional study of awareness and screening activities. The females were asked for the reasons for not undergoing breast cancer screening, the opinion about running a program with doorstep approach and opinion about the information gathered through such awareness activities and for the betterment of it.

\section{Data Analysis:}

The sociodemographic information of the study participants was entered in MS Excel and analysed. The descriptive statistics were presented as frequency and S.D. The data was collected and recorded for the open ended questions from the participant females and it was analysed through manual content analysis. The data was presented in tabular form.

\section{RESULTS}

The present interventional study was conducted in Yelakeli Village of Seloo Block in Wardha District which comes under the field practice area of Acharya Vinoba Bhave Rural Hospital. The population of females above 30years is approximately 832 . By the end of the study the total female beneficiaries in the program were 672 .

Table 1. Age-wise distribution of Study Participants

\begin{tabular}{lll}
\hline $\begin{array}{l}\text { Variable } \\
\text { Group (age in } \\
\text { years }\end{array}$ & N (\%) & Mean \pm SD \\
\hline $30-39$ & $294(43.75)$ & $33.38 \pm 2.91$ \\
$40-49$ & $193(28.72)$ & $43.59 \pm 2.74$ \\
Above 50 & $185(27.53)$ & $55.43 \pm 4.9$ \\
& 672 & $42.38 \pm 9.76$ \\
\hline
\end{tabular}

Table 1 here discusses the age distribution of the participants. It was found that majority of the females were in the age group of 30 to 39 years of age i.e. $43.75 \%$ of the total females with mean $33.38( \pm 2.91)$. While $28.72 \%$ females were in the age group of 40 to 49 years and $27.53 \%$ above the age of 50years. The total mean was found $42.38( \pm 9.76)$.

Table 2. Sociodemographic status of Study Participants

\begin{tabular}{l|l|l}
\hline Variable & Variable group & $\mathbf{N}(\mathbf{\%})$ \\
\hline \multirow{4}{*}{ Education } & Illiterate & $123(18.3)$ \\
\cline { 2 - 3 } & Primary Education & $108(16.07)$ \\
\cline { 2 - 3 } & Secondary Education & $324(48.2)$ \\
\cline { 2 - 3 } & Higher Education & $78(11.6)$ \\
\cline { 2 - 3 } Category & Graduate & $39(5.81)$ \\
\cline { 2 - 3 } & Open & $13(1.9)$ \\
\cline { 2 - 3 } & OBC & $559(83.2)$ \\
\cline { 2 - 3 } & SC/ST & $100(14.9)$ \\
\hline
\end{tabular}

Table 2 here discusses the demographic characteristics of the study participants. It shows that most of the females i.e. $48.2 \%$ females have been educated till Secondary school. This was followed by $18.30 \%$ females illiterate, $16.07 \%$ educated till Primary, $11.6 \%$ have taken secondary education and as less as $5.81 \%$ females in the village have been graduated. $83.2 \%$ of the study participants belonged to OBC category.

In the table we studied the perceptions of the beneficiary females about the breast cancer awareness and screening program.

When asked about the reasons for not undergoing screening for breast cancer most of the responses were that they cannot have breast cancer. This included responses like we can't get cancer (aahmala cancer hou shakat nahi). The second common response was the fear of mammography. The beneficiaries said that the machine is scary enough to not have the screening done. Then most of the females also pointed out towards the loss of wages. One of the response was we are daily wage workers, if we don't go even for a day, how will we eat (aamhi roj majuri waale loka, ek diwas pan nahi gelo tar paise milat nahi, mag khaaycha kasa). In the other common responses there was a social stigma. The respondents suggested that talking about breast or female problems is not considered good in the society and so the breast cancer screening is a big stigma and undergoing it and if people came to know then there is going be a lot of discussion around in the problem. Some respondents also pointed to the fact that the family, especially husbands and elderly males in the family not very supportive of undergoing screening. We don't need investigation (garaj nahi vatat chachni chi) was the response at the family level when asked about. A very few respondents also suggested that there was a lack of knowledge about the signs and symptoms of breast cancer and so they are ignorant and not going for the screening for breast cancer. 
Table 3. Perceptions of beneficiary females about the Breast Cancer Awareness

Reasons for not undergoing screening for the Breast Cancer
Cannot have breast cancer
Fear of the Mammography
Loss of daily wages
Social Stigma
Family i.e. Husband and males in the home not very supportive for undergoing screening
No knowledge of breast cancer signs and symptoms
Opinion about running the Program at the doorstep
A good option at the doorstep
Don't need to go to the hospital and spend money
Inhibitions for doing the screening with known females around while doing the test
Loss of daily wages
Opinion about the information gathered through the awareness activities
A good information about the breast cancer symptoms and signs
Knowledge gained about curability of breast cancer
Knowledge gained about Mammography and that it is harmless
Opinion about utility of a doorstep program
The Program a good way of creating awareness
Doorstep screening helps break stigma

The other open ended question asked was about the opinion on running the screening program at the doorstep. Most of the respondents considered it to be a good option at the doorstep as it becomes feasible. If test is done at doorstep, then we will do (ghari karta aali tapaasni tar aamhi nakki karu) was how most females reacted. Other common response was that it is good since they would not have to go to the hospital and spend money from their meagre wages. However a couple responses were about the inhibition about getting the investigation done as at the doorstep the other females around are known. Females in neighbourhood know us, we feel shame in doing it (aas paas chya bayka olakhtat aamhala, tyanchyasamor tapaasni karayla laaj vat te) was the response from one of the females. Also a few number of beneficiaries also responded that they would lose daily wages since they go early for work. We go to work early morning and do to the test we have to stay at home, one day wage is lost (sakalich kamala jaato aani tapaasni karayla ghari rahava lagte, eka diwasachi majuri jaate) said a couple of females.

On taking the opinion about the information they gathered through the awareness activities conducted at the doorstep, the most common response was that they have gathered a good amount of information about the breast cancer symptoms and signs through the flipcharts and door-to-door information dissemination. The social workers gave and explained information about breast cancer with photos nicely (photos dakhavun faar mahiti dili stanachya karkrogabaddal aani karmachari mahilanni changlyani samjavle) was a response from one of the beneficiary. The other common response given by the beneficiaries was now they know that the breast cancer is curable. Previously we thought that breast cancer will lead to death, but now we know if caught early, it can be cured (pahile asa vataycha ki kark rog jhala ki maran aahe pan aata mahiti aahe ki stanacha kark rog lavkar aadhalyaas bara hou shakto) said one of the beneficiary. A few respondents also said that they came to know about the fact that Mammography is harmless and a non -invasive method of knowing about the breast cancer presence and it can help in early detection.

When asked about the opinion for the utility of a pro- gram having breast cancer awareness component at doorstep, maximum respondents said that the program is a good way of creating awareness in the society. Since it is a doorstep program, the utilization of the program can be high and many females can be benefitted. We feel satisfied that they came at the doorstep and taught about breast cancer and did investigation (aamchyakade yeun aamhala shikavla aani tapaasni keli tar aamhala pan samadhan aahe aani mahiti pan milte) was a response from one of the respondents. Many of the females also suggested that because of the doorstep approach the stigma could be broken. Some respondents even said that because of the doorstep approach, even their family members, especially males in the family, are now aware of the breast cancer and importance of screening which made them support the females in their family for the screening.

\section{DISCUSSION}

The present study was setup in a rural area, Yelakeli, of Wardha district with a qualitative exploration of the views and ideas of the female participants related to breast cancer. We covered 672 female beneficiaries under our Breast Cancer Awareness and Screening Program. Our study covered majority of females i.e. $43.75 \%$ in the age group of $30-39$ years which is younger age group. Most of the females had completed secondary education i.e. $48.2 \%$ and $83.2 \%$ females in the village belonged to OBC category. This are similar to the findings of the study by Mishra et al [6] probably because of the population based approach used by them as well. Aich et al [7] in their study found that the chances of developing breast cancer were more in elderly age group, the most common being 41-50years and is less in less than 30years age group which is in favour with our study.

In the present study, $48.2 \%$ participants had completed secondary education, followed by $16.07 \%$ females who were illiterate and followed by higher education which were $11.6 \%$. Similarly, in the study by Mishra et al 2015 , most of the respondents had completed education till secondary school i.e. $64.45 \%$ which is in accordance with our study since our majority respondents had also finished studies till secondary school [6]. However the 
percentage is less, which might be due to a smaller sample size in our study due to lesser duration and smaller area covered under the study.

However in the study conducted by Dahiya et al in 2018, the respondents had completed 15 years and more of education i.e. 59.4\% [8]. This might be because of the settings of the study as their study was conducted in Delhi which is an urban setup unlike ours which is conducted in a rural setup.

In our study, most of the respondents belonged to $\mathrm{OBC}$ category which belongs to Hindu Religion i.e. $83.2 \%$. In other studies as well like Mishra et al in 2015 and Gangane et al in 2015, they saw that the most of the females belonged to Hindu category i.e. $82.98 \%$ and $78.5 \%$ respectively $[6,9]$. This is in accordance with our study. However we did not categorise the participants according to the religion and based only on the caste which the other studies have done.

In this study we performed a qualitative analysis for the perceptions of beneficiary females about breast cancer. When they were asked about the reasons for not undergoing screening for breast cancer most of the females said that they cannot have breast cancer and the second common response was the fear of mammography. A lack of knowledge of breast cancer signs and symptoms can be one very important reason why many of the cases are detected at a very late stage which hence leads to mortality. The females also have social stigma and hence they don't come out with diseases with the fear of the society. There has been a fear of Mammography amongst females much because of the invasive technique and shy nature of the females.

Most of the beneficiary females realised that if the activities are brought at the doorstep, is a great option as they don't have to spend money and time in the hospital and they can carry on their daily routine work after giving some time for investigation. However because of doorstep approach there are inhibitions due to known neighbourhood and it gets awkward getting the investigations.

We also asked for the opinion of the beneficiaries about the information gathered through the breast cancer awareness activities. Most of the study participants felt it gave a good deal of information about breast cancer signs and symptoms. There has been an increased awareness by the significant increase in the knowledge component after one year of health information dissemination which was why the activities were undertaken.

Every program has its own sets of strengths and fallacies on both, beneficiary and provider front. Hence we enquired about the opinion of betterment of program and its utility from the beneficiaries. The females appreciated the program for creating awareness and quite a few opined that the time duration should have been a longer one as more people can be covered and benefitted. This is similar with even the providers who felt the same about the program.

\section{CONCLUSION}

Program incorporating awareness and screening for breast cancer can be an effective community-based strategy in imparting knowledge and awareness among the females. It will not only helped with knowledge gain but also motivate them to practice self-breast examination and undergo clinical examination as well. It will come as a welcome change considering a growing burden of breast cancer in India.

\section{REFERENCES}

1. Cancer Statistics [Internet]. India Against Cancer. [cited 2018 Oct 11]. Available from: http:// cancerindia.org.in/statistics/

2. Chapter10_Printed.pdf [Internet]. [cited 2016 Aug 6]. Available from: http://www.ncrpindia.org/ ALL NCRP REPORTS/ PBCR REPŌRT 2012 2014/ALL CONTENT/ PDF_Printed_Version/Chapter10_Printed.pdf

3. Agarwal G, Ramakant P. Breast Cancer Care in India: The Current Scenario and the Challenges for the Future. Breast Care. 2008 Mar;3(1):21-7.

4. Operational_Guideline_NPCDCS.pdf [Internet]. [cited 201 $\overline{6}$ Aug 6]. Available from: http:// health.puducherry.gov.in/ACTS\%20AND\% 20MANUALS/ Operational_Guideline_NPCDCS.pdf

5. Valley D, KUMENG E, SIANG E, KUMEY K. District Census Handbook, Wardha, Census of India 2011. Himal Shears Hindustan Books New Delhi. :107-113.

6. Mishra GA, Dhivar HD, Gupta SD, Kulkarni SV, Shastri SS. A population-based screening program for early detection of common cancers among women in India - methodology and interim results. Indian J Cancer. 2015 Mar;52(1):139-45.

7. Aich R, Mondal N, Chhatui B, Sepai H, Aich R, Acharyya A, et al. Relevance of risk factors of breast cancer in women: An Eastern Indian scenario. J Cancer Res Ther. 2016;12(1):302.

8. Dahiya N, Basu S, Singh MC, Garg S, Kumar R, Kohli C. Knowledge and Practices Related to Screening for Breast Cancer among Women in Delhi, India. Asian Pac J Cancer Prev. 2018;19(1):155159.

9. Gangane N, Ng N, Sebastian MS. Women's Knowledge, Attitudes, and Practices about Breast Cancer in a Rural District of Central India. Asian Pac J Cancer Prev. 2015 Nov 4;16(16):6863-70. 